\title{
ANÁLISE CRÍTICA DO ACESSO À INFORMAÇÃO PÚBLICA NOS MUNICÍPIOS BAIANOS COM MAIS DE 100 MIL HABITANTES
}

\section{CRITICAL ANALYSIS OF THE ACCESS TO PUBLIC INFORMATION OF THE CITIES FROM BAHIA WITH MORE THAN 100 HUNDRED THOUSANDS INHABITANTS}

\author{
André Portella ${ }^{1}$ \\ André Quadros Côrtes²
}

\begin{abstract}
Resumo
A Constituição Federal de 1988 foi um marco histórico-normativo fundamental para o reconhecimento da relevância do acesso à informação pública enquanto ferramenta elementar ao exercício da cidadania, especialmente nas suas manifestações de controle social e soberania popular. Com efeito, é apenas a partir do acesso à informação pública que o cidadão encontra a plenitude das possibilidades de participação na vida política. Mais do que um direito fundamental a encerrar-se em si mesmo, o acesso à informação pública é meio para o exercício de muitos dos demais direitos fundamentais previstos na Carta de 88. O presente estudo propõe-se a analisar, de forma crítica, a situação atual em que se encontra o acesso à informação pública nos Municípios brasileiros. Para isso, parte de um estudo teórico voltado ao delineamento normativo do direito à informação pública, aí incluída a sua previsão constitucional, bem como na Lei de Responsabilidade Fiscal e, ainda mais recente, na Lei de Acesso à Informação Pública. Por outro lado, realiza um levantamento empírico das páginas eletrônicas dos Municípios do Estado da Bahia que tenham mais de 100 mil habitantes para verificar o estágio de regulamentação e cumprimento da legislação regente da matéria.
\end{abstract}

Palavras-chave: Acesso à Informação Pública. Transparência. Controle Social. Municípios.

\begin{abstract}
It is realized clearly from the Federal Constitution of 1988 a normative developments in the legal field of access to public information with reflection in Brazilian Municipalities, by annotated edition of the fiscal responsibility law and, more recently, the law on access to public information. These regulations reaffirm the public access to information as a fundamental right of the citizen showing the importance of this topic for the exercise of social control and consecration of valuable constitutional principle of popular sovereignty. The present study analyzed the municipal web sites to check the status of regulation and implementation of access to public information in Bahia Municipalities with more than 100000 inhabitants.
\end{abstract}

Keywords: Law of Access to Information. Public Transparency. Social Control. Regulation and Implementation. Municipality

\footnotetext{
${ }^{1}$ Doutor em Direito Financeiro e Tributário pela Universidad Complutense de Madrid, Professor de Direito Finaceiro e Tributário e de Metodologia da Pesquisa Jurídica da UFBA, Professor de Direito Tributário da UNEB e da UCSal, junto aos cursos de Graduação em Direito, Mestrados e Doutorados, e Coordenador da Especialização em Direito Tributário da UCSal. Pesquisador CNPq/FAPESB. E-mail: aaportella@nefportal.com.br.

2 Mestre em Políticas Sociais e Cidadania pela Universidade Católica do Salvador. Professor de Direito da Faculdade Batista Brasileira. E-mail: aquadroscortes@hotmail.com
} 


\section{INTRODUÇÃO}

A promulgação da Constituição Federal em 1988 embasada na soberania popular, já no discurso constituinte alçou a cidadania e a dignidade da pessoa humana à condição de valores supremos do Estado democrático de direito. Como substrato de tais valores, e como forma de assegurar a efetividade dos mesmos, tratou ainda o constituinte de dispensar tratamento especial ao acesso à informação pública, atrelada à participação da sociedade na fiscalização dos atos do poder público, consoante previsão capitulada no art. 5ㅇ, inciso XIV, XXXIII, art. 37, § 3ำ, inciso II e no art. 216, $\S 20.3$

Não obstante, ainda que considerada a garantia constitucional expressa no seu delineamento geral, a Carta da República, assentada na linha do positivismo normativo do direito brasileiro, deixou ao encargo da legislação infraconstitucional a disciplina dos procedimentos aplicáveis ao exercício deste direito de acesso a informação pública.

Um primeiro instrumento normativo voltado à regulamentação da matéria, a ser destaca é a Lei de Responsabilidade Fiscal (LRF), Lei Complementar (LC) 101/2000, que estabelece normas voltadas à responsabilidade na gestão da coisa pública nos três planos da organização políticaadministrativa do Estado brasileiro. Por outro lado, no tocante ao acesso à informação e transparência públicas, fiscalização e controle, há que se enfatizar também a edição da LC 131/2009, que acrescentou dispositivos à LRF, a fim de determinar a disponibilização, em tempo real, de informações pormenorizadas sobre a execução orçamentária e financeira dos Entes federativos, na busca da ampliação do princípio da transparência e da promoção do controle social.

Destaca-se, ainda, a Lei de Acesso à Informação (LAI), Lei 12.527/2011, que "regula o acesso a informações previsto no inciso XXXIII do art. 5ำ no inciso II do $\S 3^{\circ}-$ do art. 37 e no $\S 2^{\circ}$ do art. 216 da Constituição Federal e dá outras providências", estabelecendo um novo marco regulatório no que tange ao direito de acesso à informação pública, com o aperfeiçoamento das exigências legais, notadamente na modalidade eletrônica.

A partir da análise de tais ditames legais objetiva-se no presente estudo observar o grau de efetividade do acesso à informação pública no plano municipal do Estado da Bahia, bem como realizar

${ }^{3} \mathrm{CF} / 88$, Art. 5o, XIV: É assegurado a todos o acesso à informação e resguardado o sigilo da fonte, quando necessário ao exercício profissional; (...) XXXIII: todos têm direito a receber dos órgãos públicos informações de seu interesse particular, ou de interesse coletivo ou geral, que serão prestadas no prazo da lei, sob pena de responsabilidade, ressalvadas aquelas cujo sigilo seja imprescindível à segurança da sociedade e do Estado; (...) Art. 37, § 3으. II: o acesso dos usuários a registros administrativos e a informações sobre atos de governo, observado o disposto no art. 5ㅇ, X e XXXIII; (...) Art. 216, § 2ㅇ: Cabem à administração pública, na forma da lei, a gestão da documentação governamental e as providências para franquear sua consulta a quantos dela necessitem. 
ponderação acerca do impacto de tal acesso sobre o controle social, e sobre o exercício da participação cidadã na coisa pública, em homenagem ao Estado Democrático de Direito.

A fim de atingir o seu objetivo central consistente na análise do grau de efetividade do acesso à informação pública nos Municípios do Estado da Bahia, e com vistas à regulamentação normativa da matéria, o presente estudo adotou como parâmetros: a) a existência publicação de ato normativo local regulamentador da matéria; b) a existência de divulgação das informações relativas aos dados institucionais de receitas e despesas, licitações e contratos dos Municípios, c) a disponibilização de um sistema de perguntas frequentes da sociedade para fins de esclarecimento ao cidadão em site municipal; d) a criação de serviço eletrônico de informação pública ao cidadão; e e) a previsão normativa e a efetiva existência de instância recursal frente a eventual denegação do requerimento de informação.

O estudo foi realizado com vistas à realidade atual do Estado da Bahia, e o levantamento empírico dos dados foi realizado junto aos Municípios com mais de 100 mil habitantes, o que significou um universo de 16 Municípios. As respectivas páginas eletrônicas foram visitadas entre os dias 02 e 16 de janeiro de 2014

O critério estatístico populacional adotado justifica-se, primeiro, por que se impõe como viabilizador do estudo, na medida em que o território do Estado da Bahia encontra-se constituído por um universo de 417 Municípios, e o território brasileiro conta com mais de 5.500 entes municipais ${ }^{4}$. Em segundo lugar, sendo os Municípios selecionados os maiores em termos populacionais, os mais desenvolvidos em termos econômicos, e os mais bem estruturados na perspectiva administrativa no âmbito do Estado da Bahia, a análise da sua realidade termina por ser um indicativo qualificado da situação em que se encontra o acesso à informação nos demais Municípios do Estado.

\section{A TRANSPARÊNCIA ATIVA E PASSIVA NA NOVA LEI DE ACESSO À INFORMAÇÃO PÚBLICA}

A LAI determina os procedimentos de acesso à informação pública a serem observados pela União, Estados e Municípios, subordinando ainda toda a Administração pública direta e indireta em todas as esferas federativas e poderes da República, até mesmo para entidades privadas sem fins lucrativos que recebam recurso público para consecução das suas atividades sociais.

A informação, entendida como o conjunto dos "dados, processados ou não, que podem ser utilizados para produção e transmissão de conhecimento, contidos em qualquer meio, suporte ou formato" (LAI, art. 4ํㅡ I), sempre que em posse da Administração Pública, deve ser disponibilizada mediante procedimentos pautados na publicidade como regra geral e no sigilo como exceção, na

\footnotetext{
${ }^{4}$ IBGE (http://www.ibge.gov.br/home/estatistica/populacao/indicadores_sociais_municipais/tabela1a.shtm)
} 
divulgação de informação de interesse público independentemente de solicitações, na utilização de ferramentas de tecnologia da informação, no incentivo ao desenvolvimento da cultura da transparência e do controle social na Administração pública (LAI, arts. 3ํe 4으).

O acesso à informação pública, do ponto de vista jurídico, encontra-se pautado na ideia de transparência na sua modalidade ativa, devendo-se entender o termo na perspectiva daquele sobre quem recai o dever de prestação da informação. Isto exige que a Administração Pública proceda à divulgação por impulso próprio, dispensada a necessidade de requerimento, das informações de interesse coletivo, a exemplo da disponibilidade de informações institucionais, receitas, despesas, licitações e contratos e perguntas frequentes da sociedade em site municipal de acesso à informação.

Na hipótese da transparência na modalidade passiva a Administração Pública fornece a informação a partir da demanda realizada pelo interessado. Embora seja necessário o requerimento, é fundamental que a Administração viabilize o acesso de forma desburocratizada, com a indicação clara de todo o procedimento, inclusive no tocante à instância recursal por ventura necessária em caso de denegação da prestação da informação solicitada.

Interessante notar que, tanto no caso da transparência ativa, como passiva, a legislação estimula, quando não obriga, a realização do acesso por meio eletrônico, sempre de forma clara, objetiva e precisa. Nos termos da LAl, "é dever do Estado garantir o direito de acesso à informação, franqueada, mediante procedimentos objetivos e ágeis, de forma transparente, clara e em linguagem de fácil compreensão" (LAl, art. 5).

Mais do que prestar a informação com precisão e completude técnica, exige a legislação que a mesma seja disponibilizada em linguagem cidadã, com a clareza necessária à perfeita compreensão por parte do destinatário. A esse respeito, a Controladoria-Geral da União entende que:

Na comunicação da Administração com o cidadão a linguagem deve ser clara e objetiva. A meta é garantir a leitura fácil de informações e dados. Neste sentido, termos técnicos devem ser traduzidos para o vocabulário do dia-a-dia. Nomes de programas e ações governamentais, bem como códigos e nomenclaturas de uso da gestão na prestação de contas só serão acessíveis se o público puder compreendê-los. Um exemplo: Transferência de Renda Diretamente às Famílias em Condição de Pobreza e Extrema Pobreza é, em linguagem cidadã, o Bolsa Família. ${ }^{5}$

Em definitiva, a garantia legal do amplo acesso à informação pública, mais do que exigir a disponibilização dos dados, requer que a Administração proporcione o entendimento da informação disponibilizada com atenção à natureza da linguagem que deve respeitar e difundir critérios facilitadores de compreensão e absorção das informações por parte da sociedade.

\footnotetext{
${ }^{5}$ BRASIL, Controladoria-Geral da União. Acesso à informação pública: uma introdução à Lei 12.527, de 18 de novembro de 2011. Cartilha. Brasília: CGU, 2011, p. 23.
} 
No tocante ao veículo de publicização dos dados, a LAl exige que a Administração divulgue de forma ampla, utilizando todos os meios e instrumentos de que dispuser para conhecimento do cidadão, e obriga a utilização da internet para este fim:

Art. 8o É dever dos órgãos e entidades públicas promover, independentemente de requerimentos, a divulgação em local de fácil acesso, no âmbito de suas competências, de informações de interesse coletivo ou geral por eles produzidas ou custodiadas.

$\S 2$ ㅇ Para cumprimento do disposto no caput, os órgãos e entidades públicas deverão utilizar todos os meios e instrumentos legítimos de que dispuserem, sendo obrigatória a divulgação em sítios oficiais da rede mundial de computadores (internet).

A Lei registra um rol de dados a serem divulgados. Trata-se de um rol meramente exemplificativo, devendo ser publicado, "no mínimo" (LAI, art. 8o, $\left.\S 1^{\circ}\right)$ : a) estrutura organizacional e competências, com endereços, telefones e horários de atendimento ao público; b) repasses ou transferências de recursos financeiros; c) despesas; d) procedimentos licitatórios, editais e resultados, e contratos celebrados; e) $\mathrm{V}$ - dados gerais para o acompanhamento de programas, ações, projetos e obras de órgãos e entidades; e f) respostas a perguntas mais frequentes da sociedade.

Destaque-se a preocupação do legislador no tocante não apenas à relevância conceitual do preceito de acesso à informação pública. Mais do que isso, entra em detalhes relativos ao conteúdo da informação. Não se trata de escolha aleatória cunhada a partir de mero formalismo legal. Considera aspectos relativos à própria estrutura do Estado, nos seus aspectos político-administrativo e social.

Tal preocupação faz-se especialmente importante ao considerar que o desconhecimento dos cidadãos sobre a composição estrutural e atividades que devem ser desenvolvidas por determinado órgão público costuma obstar o exercício do controle social.

Em caráter elucidativo, Mello (2010: p.144) sintetiza que a competência dos órgãos públicos pode ser entendida como um plexo de deveres públicos a serem satisfeitos por intermédio do exercício de correlatos e demarcados poderes instrumentais, legalmente conferidos para a satisfação de interesses públicos, o que referenda ser relevante o conhecimento de tais competências como mecanismo para acompanhamento da sociedade na fiscalização dos atos públicos.

Em relação à divulgação de receitas e despesas da Administração pública, anota-se que todo orçamento e planejamento desde os simplórios aos estruturalmente mais complexos, perpassam pela necessidade do cotejo entre receitas e despesas, seu manejo e respectiva alocação, para satisfação do interesse coletivo.

Segundo Meireles (2006: p.279) classificam-se como receita orçamentária o conjunto dos recursos financeiros que entram para os cofres públicos, consoante o previsto na lei de orçamento, 
compreendendo, portanto, as rendas (recursos próprios dos tributos e preços privativos da entidade estatal) além de todos os demais ingressos, tais como os provenientes de tributos partilhados, fundos de qualquer natureza e origem, empréstimos, financiamentos, subvenções e doações.

Em complemento, ao discorrer sobre a conceituação de despesa pública Meireles (2006: p.282) assinala se tratar de todo dispêndio que a Administração faz para custear seus serviços, remuneração dos servidores, aquisição de bens, execução indireta de obras e serviços, e outros empreendimentos necessários à consecução de seus fins.

Dessa forma, conhecer o quantitativo e espécies dos recursos oriundos de arrecadação tributária própria, repasses governamentais, entre outros, assim como das despesas ordinárias e extraordinárias na condução da gestão pública é também condição necessária ao controle social, por isso compreensível a sua capitulação entre o rol mínimo obrigatório de divulgação eletrônica.

Outro ponto relevante que não pode escapar à divulgação obrigatória em meio eletrônico de acesso à informação é a apresentação dos dados gerais sobre programas, projetos, ações governamentais, obras previstas e em execução dos órgãos da Administração pública. Esta exigência auxilia o cidadão no exercício da cidadania e do controle social para acompanhamento das principais ações do governo durante o exercício do mandato de seus representantes eleitos, promovendo a ruptura de um quadro estabelecido em que tais ações e programas governamentais muitas vezes só são lembrados e apresentados de modo lacunoso em sinótico período de campanha eleitoral, sendo depois esquecidos no tempo.

No que se refere ao campo da licitação pública, Mello (2010: p. 524) acentua, em síntese, tratar-se de um certame que as entidades governamentais devem promover e no qual abrem disputa entre os interessados em com elas celebrar relações de conteúdo patrimonial, para então escolher a proposta mais vantajosa às conveniências públicas.

Desse modo, destaca-se a importância do conhecimento por parte da sociedade sobre quais bens e ou serviços estão sendo buscados pela Administração pública, os gastos públicos e os termos de sua contratação, justificada a inclusão dos procedimentos licitatórios, editais, resultados e respectivos contratos administrativos celebrados entre as informações mínimas necessárias de divulgação eletrônica nos sítios dos Entes públicos.

Ao analisar a obrigatoriedade de publicação de perguntas e respostas mais frequentes da sociedade, percebe-se que tal procedimento demanda pesquisa, compilação, revisão e divulgação por parte da Administração pública a partir de consultas reiteradas sobre determinadas matérias de interesse geral, devendo ser observada por cada Município diante de suas peculiaridades locais, sendo assim capaz de robustecer o princípio da transparência na sua modalidade ativa. 
Reitere-se que a relação dos dados a serem divulgados inclui as informações mínimas que deverão ser divulgadas, sendo dever do órgão ou entidade pública municipal definir outras informações que possam ser de interesse coletivo e que também deverão ser objeto de iniciativas de transparência ativa.

Assinala-se que o mecanismo de transparência ativa encontra-se alinhado ao princípio da publicidade dos atos administrativos e da eficiência na gestão pública uma vez que produz benefícios para o cidadão e economicidade para a Administração pública, que terá custos reduzidos na diminuição de requerimentos sobre pedidos de informação.

Por oportuno, ressalva-se que os Municípios com população de até 10.000 (dez mil) habitantes em face da menor complexidade dos seus atos administrativos ficam legalmente dispensados da divulgação obrigatória na Internet do chamado rol mínimo de informações (LAl, art. $8^{\circ}, \S 4$ ) $)$.

Em relação à transparência passiva, conforme indicado em linhas anteriores, ocorre mediante apresentação de requerimento perante órgão ou ente público para obtenção de informações de interesse coletivo, desde que não sejam resguardadas por sigilo, devendo o pedido conter a identificação do requerente e a especificação da informação requerida (LAI, art. 10).

Os requerimentos de acesso à informação dispensam motivação do pedido, pois, a regra é de que a informação pública é de propriedade da coletividade, sendo o sigilo medida excepcional, e devem ser gratuitos, salvo nas hipóteses de reprodução de documentos pelo órgão público, ressalvada a situação dos hipossuficientes (LAl, arts. 10 e 12).

Além da obrigatoriedade da implantação de um serviço de informação ao cidadão na modalidade física, com a criação de estrutura própria para atendimento dos consulentes, a LAI determina que os órgãos e entidades públicas proporcionem, em caráter complementar, meios aos cidadãos interessados para que possam encaminhar pedidos de informação mediante a utilização da Internet e gestão da informação.

No caso do Serviço eletrônico de informação ao cidadão, o interessado pode, por intermédio da Internet, realizar o pedido de informação com recebimento de número de protocolo, podendo a resposta também ser viabilizada pelo órgão público com a utilização da internet, com encaminhamento de correio eletrônico ou, ainda, acesso ao sistema virtual próprio.

Diante da negativa de acesso aos dados, tem o requerente o direito de receber comunicação com as razões da negativa e seu fundamento legal, assim como as informações para recurso, com previsão de uma instância recursal no mínimo (LAl, arts. 9 e 14). 
Desse modo, a legislação referenciada para a obtenção dos fins de amplo acesso à informação determina a obrigatoriedade de utilização de todos os meios e instrumentos legítimos de que dispuserem os órgãos e entidades públicas, sendo obrigatória a divulgação em sítios oficiais da rede mundial de computadores e obrigatória a criação do mecanismo de consulta aos interessados na modalidade do serviço de informação ao cidadão, também mediante sistema eletrônico próprio com utilização da internet.

\section{A GARANTIA DO ACESSO À INFORMAÇÃO E SUA RELEVÂNCIA PARA O CONTROLE SOCIAL}

Com o advento da Lei de Acesso à Informação em 2011, as questões atinentes à transparência na gestão pública e garantia do acesso à informação ganharam maior destaque, sendo pauta essencial a ser observada e cumprida pelos Municípios brasileiros a partir do ano de 2012, para promoção do controle social e alcance da eficiência na Administração pública.

Ao tratar da mudança e sobreposição do poder visível em face do poder invisível, Bobbio (2002: p. 117) anota que o tema mais interessante a ser destacado é o da publicidade dos atos do poder, classificando ainda como verdadeiro momento de reviravolta na transformação do Estado sob a égide do regime absolutista em Estado de direito, o que representa a formação do movimento do constitucionalismo com a inclusão de direitos fundamentais e limitação do poder estatal.

Para este estudo, relevante observar que a organização territorial do Município se comparada com os demais entes federativos possibilita uma maior aproximação entre as atividades desenvolvidas pelo poder executivo e seu impacto na vida da população, favorecendo o acompanhamento da sociedade na condução da gestão pública a partir do acesso à informação pública.

Na mesma linha de Bobbio (2002, p. 102), em um governo local a publicidade é mais direta em face da maior visibilidade dos administradores e das suas decisões. Tal entendimento costume inclusive servir de argumento aos defensores do fortalecimento do municipalismo, já que a participação popular será tanto mais visível quanto maior seja a proximidade espacial entre governante e governado.

Daí decorre, entre outros movimentos, o da realização de atos de cooperação entre os entes federativos com vistas à viabilização da transparência municipal, sobretudo mediante iniciativa e auxílio da União.

No que tange à participação popular no sistema democrático brasileiro, apregoa-se que a titularidade do poder pertence ao povo sendo o seu exercício mediante representantes eleitos, 
oportunizadas também hipóteses de manifestação direta a exemplo do plebiscito, referendo e projeto de lei de iniciativa popular, com esteio no art. $1^{\circ}$, parágrafo único, do texto constitucional.

Ocorre que o Brasil ainda retrata uma realidade na qual o seu povo muitas vezes sequer compreende o sistema basilar de representatividade política e separação dos poderes, não conseguindo diferenciar atribuições dos poderes executivo, legislativo e judiciário, menos ainda o papel do Ministério Público e dos Tribunais de Contas, configurando assim prejuízo para o exercício do controle social, não sendo suficiente o acesso à informação pública.

Em relação à garantia do acesso a informação e sua relevância para o controle social, Bobbio (2002: p. 103), argumenta que a maior ou menor relevância da opinião pública relativa aos atos públicos, atos próprios do poder público exercido, portanto, pelos órgãos decisórios do Estado, da res publica, depende da quantidade de oferta de informação à coletividade, nos seus aspectos de visibilidade, cognoscibilidade, acessibilidade e, ainda, controlabilidade dos atos de quem detém o supremo poder.

Nessa linha, Filgueiras (2000: p.75-77), estabelece um paralelo indissociável entre responsabilidade política e transparência das instituições aos cidadãos, asseverando que a consolidação do regime político democrático pressupõe uma espécie de amplo e livre conhecimento por parte do cidadão. Segundo ele, "é impossível pensar a responsabilidade política sem que as instituições sejam transparentes aos cidadãos e que o déficit de informação entre o homem comum e as instituições democráticas seja reduzido".

Oportuno, ainda, observar nas considerações de Filgueiras (2000:p.79), a necessidade de adoção de uma instância de deliberação imparcial na produção da informação, salientando que um Estado transparente por si só não garante entendimento e julgamento imparcial pela Sociedade. É necessário ademais realçar a sua capacidade cognitiva de entendimento, concluindo que na ausência de tal postura a política da transparência se revestirá como um veículo de produção de escândalos em que os aspectos relacionados às personalidades privadas prevalecerão em relação às questões públicas.

Para o exercício do controle social é preciso resgatar o conceito de cidadania no enfoque constitucionalista e social como fundamento do Estado brasileiro, conforme CF/88, art.1으, II, observando a ponderação apresentada por Silva (2012: p. 106), devendo ser entendida em sentido lato, mais amplo do que meramente os titulares de direitos políticos, classificada ainda como um 
status, qualificação do indivíduo integrado a sociedade, vinculando o funcionamento do Estado à vontade popular. ${ }^{6}$

Desse modo, a percepção restrita de aquisição e exercício da cidadania atrelada apenas ao titular de direitos políticos de votar e ser votado, alinhada ao alistamento eleitoral, não atende à demanda da participação popular e efetivo controle social.

Ao tratar da renovação da teoria democrática, Santos $(2000$, p.271) critica a restrição da participação política através apenas do ato de votar, indicando a necessidade de redefinição e ampliação acentuada do campo político. Nesse ponto, sugere uma articulação entre democracia representativa e democracia participativa fundada em radical ampliação e redefinição do campo político.

O aumento da transparência e responsabilização do poder público, segundo Abruccio (2007: p.83-84) constitui eixo estratégico da agenda de reformas com vistas à efetivação das instituições democráticas e de participação cidadã. O autor reforça os avanços observador no Brasil nos últimos anos neste campo, ressalvando, contudo, a necessidade de aprofundamento neste processo, especialmente no tocante à eficiência da administração pública e à cobrança e controle por parte da sociedade.

Nessa linha, ressalta que os múltiplos escândalos, muitos deles decorrentes da falta de transparência na gestão da coisa pública, desgastam a imagem do Estado brasileiro, enfraquecem a credibilidade da população no governo e, por conseguinte, a participação popular necessária ao controle social. Tais aspectos do Estado e da sociedade, entretanto, podem ser resgatada e fortalecidos a partir da adoção de medidas como avanços no combate à corrupção e maior transparência.

Para viabilizar a promoção da participação da sociedade e ampliação do seu conhecimento na gestão da coisa pública, Abruccio (2007, p. 83-84) sustenta a necessidade de uma modernização democratizadora, com a criação de entidades sociais independentes capazes de expandir o conhecimento sobre as ações e reflexos dos programas governamentais.

Nesse caminho, invoca uma maior contribuição do papel dos acadêmicos, dos intelectuais, da Universidade para mudança do cenário atual, como condição para entendimento sistêmico e sistemático das políticas públicas e divulgação mais acessível à população de informações acerca de indicadores e alternativas de políticas.

\footnotetext{
${ }^{6}$ Segundo a cartilha do Governo Federal de acesso à informação pública "considera-se o controle social, diante da participação do cidadão na gestão pública atuante na fiscalização, acompanhamento e controle da Administração pública, situado como relevante complemento ao controle institucional, capaz de auxiliar a eficiência na gestão pública, além de prevenção da corrupção e fortalecimento da cidadania".
} 
Reitere-se que não basta o cumprimento isolado do princípio da transparência na Administração Pública e do acesso à informação, sob pena de revestirem-se como medidas inócuas no controle social, mesmo que sejam aí incluídas medidas relativas à aplicação de novas tecnologias de disponibilização de dados por páginas eletrônicas municipais.

Nessa linha, imprescindível também o incremento de política pública visando à inclusão digital, diminuição de custos de acesso à internet, e, ainda, oficinas para atender aos que não possuam conhecimentos técnicos de acesso. Ao revés, todo o esforço de transparência e acesso à informação restaria comprometido, tornando falaciosa esta nova forma de exercício da cidadania.

Portanto, para muito além de tão somente disponibilizar a informação, é necessário reunir esforços, constituir estruturas, e instrumentalizar o cidadão, com vistas a viabilizar o acesso à informação pública ao conhecimento de qualquer indivíduo, de maneira clara, precisa e objetiva.

\section{O CUMPRIMENTO DA LEI DE ACESSO À INFORMAÇÃO PÚBLICA NOS MUNICÍPIOS BAIANOS COM MAIS DE 100 MIL HABITANTES}

A proposta para o presente estudo cingiu-se ao levantamento colhido nas páginas eletrônicas municipais com base na regulamentação e no cumprimento da Lei de acesso à informação pública pelos Municípios baianos selecionados a partir do critério estatístico populacional superior a 100 mil habitantes, resultando num universo de 16 Municípios: Alagoinhas, Barreiras, Camaçari, Eunápolis, Feira de Santana, Ilhéus, Itabuna, Jequié, Juazeiro, Lauro de Freitas, Paulo Afonso, Porto Seguro, Salvador, Simões Filho, Teixeira de Freitas, Vitória da Conquista.

Entre as exigências legais da LAl para os Municípios foram observadas a) a existência publicação de ato normativo local regulamentador da matéria; b) a existência de divulgação das informações relativas aos dados institucionais de receitas e despesas, licitações e contratos dos Municípios, c) a disponibilização de um sistema de perguntas frequentes da sociedade para fins de esclarecimento ao cidadão em site municipal; d) a criação de serviço eletrônico de informação pública ao cidadão; e e) a previsão normativa e a efetiva existência de instância recursal frente a eventual denegação do requerimento de informação.

Inicialmente, indica-se que a etapa inaugural da regulamentação do acesso à informação no âmbito local consiste na edição, por parte do Município, de ato normativo próprio, com previsão específica de procedimentos e rotinas calcadas na respectiva realidade da estrutura políticoadministrativa e social, visando suplementar a legislação federal.

Revista de Direito da Cidade, vol.07, no 03. ISSN 2317-7721 pp.1092-1111 1102 
Nessa senda, verifica-se que apenas três Municípios entre os pesquisados editaram ato normativo próprio, sendo eles Alagoinhas, Itabuna e Salvador, o que representa apenas $18,75 \%$ de cumprimento de regulamentação normativa. ${ }^{7}$

Registre-se, entretanto, a dificuldade encontrada para ter acesso a tais dados. Com efeito, após uma intensa e infrutífera pesquisa nas páginas institucionais destes Municípios, restou apenas a opção de realização de um levantamento por meio de páginas de busca. Não há, portanto, uma disponibilização da regulamentação por meio de atalho em página do próprio Município, o que é contraditório com a sistemática da transparência ativa.

Para análise da situação enfrentada em cotejo com o cenário nacional, apresenta-se levantamento produzido pela Controladoria Geral da União (CGU), por intermédio do programa denominado Brasil Transparente, com os seguintes índices de regulamentação da LAl nos Estados e Municípios brasileiros, em janeiro de 2014, destacando que a pesquisa alcançou os 26 Estados, o Distrito Federal, 26 Capitais e 254 Municípios com população superior a cem mil habitantes. ${ }^{8}$

Regulamentação da LAl pelos Entes Federativos - Janeiro de 2014

\begin{tabular}{|c|c|}
\hline Estados e o Distrito Federal & $73 \%$ \\
\hline Capitais & $65 \%$ \\
\hline Municípios brasileiros com mais de 100 mil (cem mil) habitantes & $24 \%$ \\
\hline
\end{tabular}
(Fonte: elaborada pelos autores com base nos dados coletados pela CGU no Programa Brasil transparente)

No que diz respeito à existência de página eletrônica de transparência e acesso à informação, verifica-se que a totalidade do Municípios pesquisados cumprem com tal requisito. Não obstante, e sem prejuízo da análise relativa ao conteúdo dos dados e qualidade da linguagem utilizada, apenas 9 Municípios, o que equivaleria a 56,25\% do universo, utilizaram página eletrônica oficial padronizada, com extensão "gov.br", sendo eles Alagoinhas, Camaçari, Feira de Santana, Itabuna, Juazeiro, Lauro de Freitas, Salvador, Simões Filho e Vitória da Conquista. Os restantes adotaram criação de site sem a padronização oficial, o que constituiria uma irregularidade formal, eventualmente limitadora do acesso.

Não é demais recordar neste ponto a determinação legal para que os Municípios divulguem as informações de interesse público obrigatoriamente em sítios oficiais da rede mundial de

\footnotetext{
${ }^{7}$ Em cumprimento à regulamentação da LAl o Município de Alagoinhas editou a Lei municipal n. 2.177/2012, o de Itabuna editou o Decreto municipal n. 10.651/2013 e o de Salvador editou a Lei municipal n. 8.460/2013.

8 Do levantamento apresentado pela CGU, janeiro de 2014, verifica-se que foi localizada a regulamentação da LAI no Distrito Federal e 19 Estados (Alagoas, Bahia, Ceará, Espírito Santo, Goiás, Minas Gerais, Mato Grosso, Mato Grosso do Sul, Paraíba, Pernambuco, Piauí, Paraná, Rio de Janeiro, Rondônia, Rio Grande do Sul, Santa Catarina, Sergipe, São Paulo e Tocantins); e, em 17 Capitais (Belém, Belo Horizonte, Campo Grande, Curitiba, Florianópolis, Goiânia, João Pessoa, Manaus, Natal, Palmas, Porto Alegre, Recife, Rio Branco, Rio de Janeiro, São Paulo e Vitória).
} 
computadores, em conformidade com a LAl, art. $8^{\circ}$,,$\S \S 1^{\circ}$ e $2^{\circ}$. Não se trata de mera formalidade, mas de aspecto técnico que pode ensejar óbice ao acesso direto à página pretendida. Em definitiva, disponibilizar informações avulsas ou em páginas eletrônicas municipais desprovidas da oficialidade e padronização, escapa ao propósito da transparência ativa dificultando ao cidadão a localização e fácil acesso às informações de caráter público.

Por outro lado, a existência de página eletrônica municipal oficial, ainda que submetida à padronização exigida não se traduz em efetividade plena da disponibilidade de acesso à informação pública ao seu conteúdo, nos termos pretendidos pelo legislador. Interessante notar, neste sentido, que os Municípios de Alagoinhas, Ilhéus, Itabuna, Lauro de Freitas e Paulo Afonso apresentaram, à primeira vista, o cumprimento do requisito de criação de página eletrônica de transparência e acesso à informação municipal, entretanto os portais continham inconsistência de acesso de uma forma geral, assim como no que se refere a campos virtuais específicos, de forma a obstar o acesso à informação pública.

Já no que se refere aos Municípios de Barreiras, Camaçari, Eunápolis, Jequié, Feira de Santana, Juazeiro, Porto seguro, Salvador, Simões Filho e Teixeira de Freitas foi observada a existência de insuficiência de disponibilidade de informações obrigatórias, assim como informações desatualizadas, reiterando-se o descumprimento da LAI.

Em relação à disponibilidade de acesso a informações institucionais referente à Administração Pública verificou-se o cumprimento da normativa apenas em parte dos Municípios, equivalente a 31,5\%. São eles os Municípios de Feira de Santana, Jequié, Porto Seguro, Teixeira de Freitas e Vitória da Conquista. Nos demais Municípios furta-se às respectivas populações as informações relativas à estrutura da Administração, bem como à gestão da coisa pública.

Ressalte-se a importância que têm tais dados enquanto vetores de promoção do exercício da cidadania e promoção do controle social. A divulgação de tais dados institucionais no âmbito municipal se propõe a apresentar à população os principais responsáveis pelas pastas e agendas municipais, aclarar na estrutura administrativa os deveres institucionais de cada órgão, quais as suas atribuições e competências, assim como os endereços, horários e telefones para contato.

No tocante à divulgação de receitas e despesas, exigência já contida na LRF, reiterada pela LAI, verifica-se cumprimento por parte de $75 \%$ dos Municípios pesquisados, aí incluídos Barreiras, Camaçari, Eunápolis, Feira de Santana, Ilhéus, Jequié, Juazeiro, Porto Seguro, Salvador, Simões Filho, Teixeira de Freitas e Vitória da Conquista.

Reitera-se que as receitas e despesas públicas são alguns dos elementos centrais de organização dos atos da Administração pública pelo que se acentua a responsabilidade em divulgar 
estes dados nos sítios eletrônicos municipais de transparência e acesso à informação, inclusive com a utilização de linguagem clara e de fácil compreensão, desafio a ser enfrentado pelas Administrações públicas municipais.

O conhecimento dos valores das receitas que compõem o orçamento municipal propicia ao cidadão, entre outras coisas, a ponderação da qualidade das alocações financeiras, e o juízo sobre a prioridade dos gastos a serem realizados. Numa análise mais criteriosa, são dados que possibilitam até mesmo a compreensão de temas fundamentais à realidade do Estado e da sociedade brasileira, tais como os da efetividade do regime federativo, da estrutura de financiamento dos entes políticos, da autonomia financeira municipal a Estados e sobretudo à União, a dependência das verbas federais para execução de políticas públicas, entre outros temas relevantes.

No que tange à disponibilidade de informações sobre licitações e contratos, também exigida pela LRF e reiterada pela LAI, verifica-se um percentual de cumprimento de $62,5 \%$ dos Municípios pesquisados, entre os quais, Barreiras, Eunápolis, Feira de Santana, Jequié, Juazeiro, Paulo Afonso, Porto Seguro, Simões Filho, Teixeira de Freitas e Vitória da Conquista.

É preciso considerar que a divulgação de licitações e contratos administrativos realizados pelos Municípios é de fundamental importância para o acompanhamento das obras, programas, atividades gerais e gastos públicos por parte dos cidadãos e dos órgãos de controle institucional, visando assim coibir práticas reiteradas de corrupção em certames licitatórios comumente utilizados como verdadeiros sumidouros de recursos públicos.

Em relação à disponibilidade de perguntas frequentes da sociedade, verifica-se que o equivalente a apenas $12,5 \%$ dos Municípios cumprem a exigência. O Município de Salvador atendeu satisfatoriamente a referida exigência legal, inclusive com a criação de glossário relativos a grupos de questões e palavras-chave. Já o Município de Vitória da Conquista apenas reproduziu questões gerais previstas na LAI.

A sistematização de perguntas frequentes da sociedade disponibilizadas em página eletrônica municipal de acesso a informação implica, entre outras coisas, a redução do volume de consultas virtuais e presenciais. Assim, além de constituir meio para se atingir o desiderato da transparência e fomento à participação e controle social, esta exigência legal termina por contribuir para com a agilidade de procedimentos, racionalidade no emprego de recursos, inclusive recursos humanos, e diminuição de gastos.

Na questão da criação de um Sistema de Informação eletrônico ao Cidadão - SIC eletrônico, verifica-se que apenas quatro Municípios atenderam a esta exigência legal, entre eles, Eunápolis, Feira de Santana, Itabuna e Vitória da Conquista, o que equivale a $25 \%$ do universo examinado. A fim de 
verificar a efetividade do atendimento, foi apresentada de consulta virtual, verificando-se o recebimento de resposta apenas nos Municípios de Itabuna e Vitória da Conquista.

A rigor, não há outra alternativa a considerar senão a de equiparar um SIC-eletrônico inoperante à inexistência de tal sistema, ao menos para fins de enquadramento normativo. Com efeito, a mera criação formal de uma página indicativa de sistema de serviço de informação eletrônico ao cidadão, ou ainda implantação do sistema, contudo sem resposta às consultas formuladas, é igualmente medida inócua para a efetividade do direito de acesso à informação.

A finalidade desse novo instrumento virtual de informação ao cidadão é dinamizar a relação entre o consulente e os órgãos da Administração pública gerando uma maior comodidade, praticidade, assim como incentivo com mais um veículo de comunicação para o exercício da cidadania e participação popular.

Já no que se refere à exigência legal de previsão de instância recursal para hipótese de negativa de acesso a informação pública, verifica-se que apenas três Municípios, Alagoinhas, Itabuna e Salvador, atenderam a esta exigência legal, representando assim um percentual de 18,75\%.

A previsão legal de instância recursal não garante o exercício do direito de combater negativa de pedido de informação, pois como visto apesar da criação de instância recursal no seu aspecto formal pelos Municípios de Alagoinhas e Salvador, sequer foi criado o serviço eletrônico de informação ao cidadão o que já inviabiliza até mesmo o pedido virtual inaugural, e por conseguinte obsta a etapa posterior de enfrentamento recursal.

As tabelas a seguir sintetizam os percentuais de acordo com as informações levantadas em páginas eletrônicas municipais pesquisadas nos critérios indicados neste estudo a partir das exigências legais de acesso à informação pública disciplinada pela LAI.

Regulamentação da LAI nos Municípios baianos com mais de 100 mil habitantes - Janeiro de 2014.

\begin{tabular}{|c|c|}
\hline Criação de Lei/ ato normativo municipal & $18,75 \%$ \\
\hline Criação de Sistema de Informação ao Cidadão - SIC eletrônico & $25 \%$ \\
\hline Previsão de Instância Recursal & $18,75 \%$ \\
\hline
\end{tabular}

(Fonte: elaborada pelo autor com base nos dados coletados nos sites municipais)

Divulgação de informações públicas nos sites dos Municípios baianos com mais de 100 mil habitantes - Janeiro de 2014.

\begin{tabular}{|c|c|}
\hline Informações institucionais & $31,25 \%$ \\
\hline Receitas e despesas & $75 \%$ \\
\hline Licitações e contratos & $62,5 \%$ \\
\hline Perguntas frequentes & $12,5 \%$ \\
\hline
\end{tabular}

(Fonte: elaborada pelo autor com base nos dados coletados nos sites municipais) 
Destaque-se que a regulamentação da informação no nível dos Municípios é apenas o passo preambular sendo imperioso atentar que as medidas de acesso à informação pública já poderiam se encontrar em fase mais avançada, especialmente diante da base dos princípios constitucionais e legislação de responsabilização na gestão fiscal, contudo ainda denota baixa efetividade nas posturas adotadas na gestão pública em sua estrutura política e social.

Endossando crítica à necessidade de efetivação do sistema e instrumentos já existentes, Abruccio (2007: p.83-84) salienta que o Brasil criou uma série de instrumentos e arenas participativas capazes de estabelecer controle político e social dos agentes governamentais, mas, a despeito da possibilidade de implementá-los, destaca como problema central fazer valer o sistema e as normas já existentes, convocando os Tribunais de contas, conselhos de políticas públicas e ouvidorias a cumprir efetivamente as funções institucionais estabelecidas.

Assim, tão importante quanto a competência legislativa suplementar dos Municípios a respeito do acesso à informação pública, é o planejamento e organização administrativa para cumprimento dos requisitos legais comprometidos com a transparência e o direito fundamental de acesso à informação, um dos valores mais caros da República ao lado da cidadania e da dignidade da pessoa humana, em consonância com o quanto apregoado pelo texto constitucional.

\section{CONSIDERAÇÕES FINAIS}

Exposta a qualificação do cidadão alinhado ao exercício da cidadania é preciso observar que para a sua participação ativa como ator de modificação e fiscalização da realidade social, individualmente ou por associação, essencial a obtenção de informações relativas às atividades desenvolvidas pela Administração Pública.

Observa-se que a própria Constituição Federal de 1988 longe se encontra de ter alcançado a plenitude dos seus objetivos, mas certamente sinaliza o aprimoramento social e jurídico, o que se espera ser o caso também da comentada LAI, sancionada em 18 de novembro de 2011, com vigência a partir de 2012, após 180 dias da sua publicação, não podendo deixar de perceber tratar-se de marco regulatório recente no ordenamento jurídico em fase de amadurecimento social.

Diante dos dados coletados, observa-se que o cumprimento da LAI de acesso à informação nos Municípios baianos com mais de 100 mil habitantes, seja no tocante à edição de ato normativo local, ou, até mesmo ao cumprimento dos requisitos de disponibilidade obrigatória nas páginas eletrônicas municipais de transparência e acesso a informação, ainda é inexpressivo, tanto do ponto de vista formal, como de conteúdo, e requer desenvolvimento cooperado entre os entes federativos para atingir os fins buscados pela lei protetiva do direito de acesso à informação pública.

Revista de Direito da Cidade, vol.07, no 03. ISSN 2317-7721 pp.1092-1111 1107 
Constata-se que a deficiência na regulamentação do acesso à informação com edição de ato normativo local ultrapassa as fronteiras do Estado da Bahia, sendo de 18,75\% o percentual de descumprimento para os Municípios baianos pesquisados e de $24 \%$ para os demais municípios brasileiros com mais de 100 mil habitantes.

Na questão de criação de sítio municipal na internet para cumprimento da transparência e acesso à informação, verifica-se que os Municípios pesquisados atingiram o cumprimento formal de criação de página na internet vinculada a transparência e acesso à informação pública municipal, criando uma ilusória percepção de cumprimento da LAI, mas descuidaram do seu conteúdo com informações incompletas e desatualizadas e, até mesmo sem efetivo funcionamento no acesso dos campos criados para divulgação das informações públicas exigidas, tudo em flagrante descumprimento do acesso à informação pública.

Outrossim, a informação, por si só, decorrente da transparência pública e do acesso à informação garantida pela legislação regente não é capaz de alterar o quadro de transformação social, precisa ser ampla, clara e de fácil compreensão. Nesse ponto, demonstra-se a importância da preparação e incentivo do indivíduo para o exercício da cidadania utilizando como ferramenta a tecnologia da informação, dever conjunto do Estado e da Sociedade.

Outro ponto merecedor de destaque é que a linguagem adotada como regra nas páginas eletrônicas municipais pesquisadas não cuidou em disponibilizar informação de fácil compreensão. Ao revés, exige do interessado conhecimentos específicos na seara contábil, orçamentária e jurídica, sobretudo no que tange à divulgação de informações das receitas e das despesas públicas. Ressentese, por exemplo, a ausência mesmo de glossários, obstando dessa maneira a efetividade do direito essencial à informação pública.

Anota-se que alguns dos ditames já exigidos pela LRF, que foram reiterados pela LAI, apresentaram um cumprimento mais significativo, a exemplo da exigência de publicidade e divulgação em sítios oficiais de receitas, despesas, bem como licitações e contratos administrativos.

Já em relação às novas informações para divulgação nas páginas de transparência e acesso à informação, a exemplo da divulgação dos dados e informações da estrutura dos órgãos e instituições, assim como inclusão nas páginas da internet de roteiro sobre perguntas e respostas mais frequentes da sociedade apresentaram menor índice de cumprimento por parte dos Municípios pesquisados.

Este panorama sugere, contudo, que após um maior lapso temporal também melhorarão os índices de cumprimento dos requisitos específicos condicionados pela LAI, de maneira mais célere ou lentamente reduzida no tempo, a depender especialmente da organização e promoção do controle 
social e institucional aplicável, da fiscalização por parte do Ministério público e também da condução dos expedientes administrativos e judiciais de sanção diante da omissão no cumprimento da lei.

Tal situação retrata a pouca organização administrativa e principalmente gerencial dos Municípios para atendimento das novas exigências legais de acesso à informação pública. Isto se faz especialmente notório diante da necessidade de modernização da gestão pública, com a necessidade de contratação dos novos serviços, utilização de ferramentas de tecnologia da informação, preparação dos servidores municipais para atuar diante das novas regras no acesso à informação pública, convocação e estímulo da sociedade para participação na gestão pública municipal.

Desse modo, denota-se que os Municípios baianos pesquisados, apresentam baixo, ou em alguns casos, nenhum cumprimento efetivo dos requisitos mínimos das novas regras do direito de acesso à informação pública. Isto demanda do Gestor público maior comprometimento com um novo olhar da Administração pública para alcance do princípio da transparência e consectário controle social, utilizando-se inclusive da cooperação com os demais Entes Federativos, especialmente à União, quando se fizer necessário.

Demonstra, sobretudo, as dificuldades de ruptura de um sistema político-administrativo pautado na cultura do segredo, agora precisando adaptar-se à nova conjuntura da transparência máxima na gestão pública, do amplo acesso à informação nas modalidades ativa e passiva.

Registra-se o acesso à informação como parte integrante, mas não exclusiva, da produção e mobilização social de responsabilidade dos Entes Públicos e também da sociedade civil organizada, no exercício da cidadania, para conduzir o controle social ao alcance da eficiência na Administração Pública.

\section{REFERÊNCIAS}

ABRUCIO, Fernando. Trajetória recente da gestão pública brasileira: um balanço crítico e a renovação da agenda de reformas. Rev. Adm. Pública vol.41, Rio de Janeiro , 2007.

BOBBIO, Norberto. A era dos direitos. Rio de Janeiro: Campus, 1992. O Futuro da Democracia. 7 Ed. Rio de Janeiro: Paz e Terra, 2002.

BRASIL, Presidência da República: Constituição da República Federativa do Brasil. Brasília: Gráfica do Senado Federal. Disponível em: www.presidencia.gov.br.

Lei Complementar, n. 101/2000. Disponível em: www.presidencia.gov.br. Lei Complementar n. 131/2009. Disponível em: www.presidencia.gov.br. Lei Federal n. 12.527/2011. Disponível em: www.presidencia.gov.br.

BRASIL. Controladoria-Geral da União. Acesso à informação pública: uma introdução à Lei 12.527, de 18 de novembro de 2011. Cartilha. Brasília: Imprensa Nacional, 2011. Disponível em: 
http://www.acessoainformacao.gov.br/central-de-

conteudo/publicacoes/cartilhaacessoainformacao.pdf. Acesso em 09.11.2014.

Acesso à informação pública: MANUAL da Lei de Acesso à Informação para Estados e Municípios.

1 ed. Brasília: Imprensa Nacional. 2013. Disponível em: http://www.cgu.gov.br/Publicacoes/transparencia-publica/brasil-

transparente/arquivos/manual_lai_estadosmunicipios.pdf. Acesso em 09.11.2014.

Guia técnico de regulamentação da Lei de Acesso à Informação em Municípios e check list. 1 ed. Brasília: Imprensa Nacional, 2013. Disponível em: http://www.cgu.gov.br/Publicacoes/transparenciapublica/brasil-transparente/arquivos/guia_checklist.pdf. Acesso em 09.11.2014.

Guia para criação da Seção de Acesso à Informação nos sítios eletrônicos dos Órgãos e Entidades Estaduais e Municipais. 1 ED. Brasília: Imprensa Nacional, 2013. Disponível em http://www.cgu.gov.br/Publicacoes/transparencia-publica/brasil-

transparente/arquivos/guia_transparenciaativa_estadosmunicipios.pdf. Acesso em 09.11.2014.

CARVALHO SILVA, José dos Santos: Manual de direito administrativo. 19 ed. SP: Lumenjuris, 2007.

CUNHA JÚNIOR, DIRLEY DA. Curso de direito administrativo. 11. ed. Salvador: Jus Podivm, 2012.

DAGNINO, Evelina. "Sociedade civil, espaços públicos e a construção democrática no Brasil: limites e possibilidades". In: DAGNINO, Evelina (org.) Sociedade civil e espaços públicos no Brasil. São Paulo: Paz e Terra, 2002.

FILGUEIRAS, Fernando. Além da transparência: accountability e política da publicidade. SP: Lua Nova, 2011.

PAULA, Ana Paula Paes de. Por uma nova gestão pública. SP: FGV, 2005.

MEIRELLES, Hely Lopes. Direito municipal brasileiro. 13 Ed. São Paulo: Malheiros, 2006.

MELLO, Celso Antônio Bandeira de. Curso de direito administrativo. 27 Ed. SP: Malheiros editores, 2010.

MENDES, Gilmar Ferreira; COELHO, Inocênio Mártires; BRANCO, Paulo Gustavo Gonet. Curso de direito constitucional. 5 Ed. São Paulo: Saraiva, 2010.

MORAES, Alexandre de. Direito constitucional. 26 Ed. São Paulo: Atlas, 2010.

SANTOS, Boaventura de Souza (org.): O social e o político na pós-modernidade, São Paulo: Cortez, 2000.

Democratizar a democracia: os caminhos da democracia participativa. Rio de Janeiro: Civilização Brasileira, 2002.

SARAIVA, Enrique. "Introdução à teoria da política pública" In: SARAIVA, E. e FERRAREZI, E. (orgs.). Políticas Públicas. Coletânea. Brasília: ENAP, 2006.

SILVA, José Afonso da. Curso de direito constitucional positivo. 32 Ed. São Paulo: Malheiros, 2009.

SPECK, Bruno Wilhem. Caminhos da Transparência. Disponível em: http://www.transparencia.org.br/Source/index.htm 
TEMER, Michel, Elementos de direito constitucional. 22 Ed. SP: Malheiros Editores, 2008.

Trabalho enviado em 02 de junho de 2015.

Aceito em 20 de julho de 2015. 